\title{
Permeability Variation Models for Unsaturated Coalbed Methane Reservoirs
}

\author{
Yumin Lv ${ }^{1,2 *}$, Zhiping Li ${ }^{1}$, Dazhen Tang ${ }^{1}$, Hao Xu ${ }^{1}$ and Xiaozhi Chen ${ }^{2}$ \\ 1 School of Energy Resources, China University of Geoscience, Beijing 100083 - China \\ 2 New Energy Research Center, CNOOC Research Institute, Beijing 100027 - China \\ e-mail: yale1210@163.com \\ * Corresponding author
}

\begin{abstract}
A large number of models have been established to describe permeability variation with the depletion of reservoir pressure to date. However, no attempt has been made to draw enough attention to the difference in the effect of various factors on permeability variation in different production stages of unsaturated CoalBed Methane (CBM) reservoirs. This paper summarizes the existing and common permeability models, determines the relationship between various effects (effective stress effect, matrix shrinkage effect and Klinkenberg effect) and desorption characteristics of the recovery of unsaturated CBM reservoirs, then establishes two improved models to quantificationally describe permeability variation, and finally discusses the effects of various factors (gas saturation, cleat porosity, Poisson's ratio and shrinkage coefficient) on permeability variation. The results show that permeability variation during the recovery of unsaturated CBM reservoirs can be divided into two stages: the first one is that permeability variation is only affected by the effective stress effect, and the second is that permeability variation is affected by the combination of the effective stress effect, matrix shrinkage effect and Klinkenberg effect. In the second stage, matrix shrinkage effect and Klinkenberg effect play much more significant role than the effective stress effect, which leads to an increase in permeability with depletion of reservoir pressure. Sensitivity analysis of parameters in the improved models reveals that those parameters associated with gas saturation, such as gas content, reservoir pressure, Langmuir volume and Langmuir pressure, have a significant impact on permeability variation in the first stage, and the important parameters in the second stage are the gas content, reservoir pressure, Langmuir volume, Langmuir pressure, Poisson's ratio, Young's modulus and shrinkage coefficient during the depletion of reservoir pressure. A comparative study of the improved models indicates that the improved SD model has a greater sensitivity to various parameters than the improved PM model and the improved models describe permeability dynamic variation more exactly than the original ones.
\end{abstract}

Résumé - Modèles de variation de perméabilité pour des réservoirs de gaz de houille insaturé Un grand nombre de modèles ont été établis à ce jour pour décrire la variation de perméabilité en fonction de l'épuisement de la pression du réservoir. Toutefois, aucune tentative n'a été faite pour attirer suffisamment l'attention sur la différence d'effet des différents facteurs sur la variation de perméabilité dans différentes phases de production des réservoirs de gaz de houille insaturés (CoalBed Methane, CBM). Le présent article résume les modèles de perméabilité existants et usuels, détermine la relation entre les différents effets (effet de contrainte effective, effet du rétrécissement 
de la matrice et effet Klinkenberg) et les caractéristiques de désorption pour la récupération des réservoirs de CBM insaturé, puis établit deux modèles améliorés pour décrire de manière quantitative la variation de perméabilité, et enfin discute des effets de différents facteurs (saturation en gaz, porosité traversante, coefficient de Poisson et coefficient de retrait) sur la variation de la perméabilité. Les résultats montrent que la variation de perméabilité pendant la récupération des réservoirs de CBM insaturé peut être divisée en deux phases : la première pour laquelle la variation de perméabilité n'est affectée que par l'effet de contrainte effectif et la seconde pour laquelle la variation de perméabilité est affectée par la combinaison de l'effet de contrainte effectif, de l'effet de retrait de matrice et de l'effet Klinkenberg. Dans la seconde phase, l'effet de retrait de matrice et l'effet Klinkenberg jouent un rôle plus significatif que l'effet de contrainte effectif, qui mène à une augmentation de la perméabilité lors de l'épuisement de la pression du réservoir. L'analyse de sensibilité des paramètres dans ces modèles améliorés révèle que les paramètres associés à la saturation en gaz, tels que la teneur en gaz, la pression du réservoir, le volume de Langmuir et la pression de Langmuir, ont un impact significatif sur la variation de perméabilité dans la première phase. Les paramètres importants dans la seconde phase pendant l'épuisement de la pression du réservoir sont la teneur en gaz, la pression du réservoir, le volume Langmuir, la pression Langmuir, le coefficient de Poisson, le module de Young et le coefficient de retrait. Une étude comparative des modèles améliorés indique que le modèle SD amélioré a une sensibilité aux différents paramètres supérieure au modèle PM amélioré et les modèles améliorés décrivent la variation dynamique de perméabilité de manière plus exacte que les modèles d'origine.

\section{NOMENCLATURE}

$V_{L} \quad$ Langmuir storage capacity $\left(\mathrm{m}^{3} / \mathrm{t}\right)$

$V \quad$ Gas storage capacity in the condition of pressure $p\left(\mathrm{~m}^{3} / \mathrm{t}\right)$

$P_{L} \quad$ Langmuir pressure (MPa)

$P \quad$ Pressure (MPa)

$p_{i} \quad$ Initial reservoir pressure (MPa)

$p_{c} \quad$ Critical desorption pressure (MPa)

$k \quad$ Reservoir permeability at the pressure of $p(\mathrm{mD})$

$k_{i} \quad$ Initial reservoir permeability $(\mathrm{mD})$

$k_{g} \quad$ Gas-phase permeability $(\mathrm{mD})$

$k_{\infty} \quad$ Absolute permeability $(\mathrm{mD})$

$\varphi_{i} \quad$ Initial porosity (-)

$\varphi_{\mathrm{c}} \quad$ Porosity at the critical desorption pressure (-)

$c_{m} \quad$ Coal compressibility (1/MPa)

$c_{f} \quad$ Cleat volume compressibility (1/MPa)

$\varepsilon_{l} \quad$ Langmuir-type matrix shrinkage constant (-)

$\sigma_{\mathrm{h} 1} \quad$ Stress in the $h 1$ direction (MPa)

$\sigma_{\mathrm{h} 2} \quad$ Stress in the $h 2$ direction (MPa)

$b \quad$ Klinkenberg coefficient (MPa)

$b_{c} \quad$ Klinkenberg coefficient at the critical desorption pressure (MPa)

$K \quad$ Bulk modulus (MPa)

$M \quad$ Constrained axial modulus (MPa)

$\vartheta \quad$ Poisson's ratio (-)

C Proportionality factor (-) $\lambda \quad$ Mean free path of gas molecules (m)

$r \quad$ Pore size radius $(\mathrm{m})$

\section{INTRODUCTION}

Coal reservoir physical properties (particularly permeability) are affected by several factors and show dynamic variation through the recovery of CoalBed Methane (CBM). These factors can be summarized as follows: the effective stress effect [1-7], matrix shrinkage effect [8-19] and Klinkenberg effect [20]. To date, the impacts of the first two effects on permeability variation in CBM reservoirs have been intensively studied [10, 13, 14, 20-44]. However, these two effects on permeability dynamic variation in different development stages of CBM reservoirs, especially in unsaturated CBM reservoirs, have not been investigated in depth. Additionally, the third Klinkenberg effect has seldom been considered in permeability variation of the recovery of CBM reservoirs.

It is widely thought that coal can be substantially unsaturated with thermogenic gas if not augmented by hydrocarbon migration or late-stage bacterial methanogenesis [45-58]. In consideration of this fact, we improved the existing permeability models in this paper to make them more suitable for describing permeability dynamic variation in unsaturated CBM reservoirs based on the production performance of those reservoirs, and discuss the sensitivity of various 
parameters, including the gas content, initial reservoir pressure, Langmuir volume and pressure, Poisson's ratio, Young's modulus, Langmuir strain, and Klinkenberg coefficient, to permeability dynamic variation in the recovery of unsaturated $\mathrm{CBM}$ reservoirs.

\section{RECOVERY MECHANISM OF UNSATURATED CBM RESERVOIRS}

Gas saturation in coal reservoirs is defined as the percentage of adsorbed gas content relative to adsorption capacity in the in situ reservoir conditions. Thus, unsaturated CBM reservoirs refer to those reservoirs in which gas content is less than their maximum gas adsorption in the reservoir conditions. Most coal reservoirs can be substantially unsaturated with thermogenic gas [45-58]. Gas saturation of coal reservoirs in the Weibei CBM field ranges from $39.2 \% \sim 87.2 \%$ [55, 56]. The micro-pilot test results showed that the gas saturation is $40.8 \%$ in the anthracitic coals of the South Qinshui basin, China [58]. Seam 4 in the Lower Cretaceous Gates Formation, Inner Foothills of Alberta showed gas saturation levels of $90 \%$ in the in situ reservoir conditions [53]. Unsaturated CBM reservoirs initially produce CBM only when the reservoir pressure is reduced below the critical desorption pressure [59, 60]. A small degree of unsaturation can necessitate prolonging dewatering period before a large reservoir volume can reach the critical desorption pressure [57]. Therefore, most discovered CBM reservoirs are unsaturated, which often leads to significant differences in production performance from high-saturated CBM reservoirs.

A variety of models have been established to describe the sorption process [61-67]. However, the most commonly used model for the gas adsorption capacity in coal is the Langmuir isotherm model, which can be used for both single-component and multicomponent gases, given by the equation below:

$$
V=V_{L} \frac{p}{p+P_{L}}
$$

where: $V$ is the gas storage capacity in the condition of pressure $p, \mathrm{~m}^{3} / \mathrm{t} ; V_{L}$ is the Langmuir storage capacity, $\mathrm{m}^{3} / \mathrm{t} ; p$ is the pressure, $\mathrm{MPa} ; P_{L}$ is the Langmuir pressure, MPa.

The area below the Langmuir isotherm curve refers to unsaturated CBM reservoirs, while the other area indicates oversaturated ones (Fig. 1). An important term established from the Langmuir isotherm curve is the critical desorption pressure, which a well situated in unsaturated reservoirs must be reduced to in order for CBM desorption to occur. Once the well pressure is higher than the critical desorption pressure, there will not be any appreciable desorption.

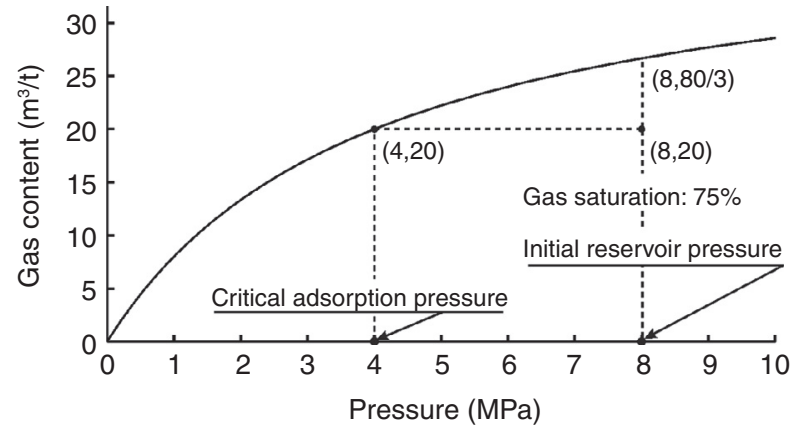

Figure 1

The Langmuir isotherm curve and the recovery of unsaturated CBM reservoirs.

Therefore, unsaturated $\mathrm{CBM}$ reservoirs do not produce $\mathrm{CBM}$ at the dewatering stage and CBM initially desorbs from the internal surface of the coal matrix only after the reservoir pressure is reduced to the critical desorption pressure and goes on $[59,60]$. Thus, a small degree of unsaturation can necessitate widening the pressure drop to produce gas for CBM reservoirs and prolong dewatering before a large reservoir volume can reach the critical desorption pressure [57].

\section{DYNAMIC MODELS OF PERMEABILITY VARIATION FOR UNSATURATED CBM RESERVOIRS}

Permeability is an important reservoir parameter determining whether the CBM reservoir can be commercially developed. Thus, it is necessary to research reservoir permeability, especially its variations with pressure. To date, a substantial number of models [4-6, 10, 13, 14, 21-28, 30, 32, 33, 36-38, $40,44]$ for permeability variations in coal have been established to attempt to account for the effect of effective stress as well as matrix shrinkage on permeability variation during the recovery of CBM reservoirs. The most widely used permeability models are the Seidle and Huitt model (SH), Palmer and Mansoori model (PM) and Shi and Durucan model (SD), as shown in Table 1.

However, all the models do not consider the effect of adsorbed gas saturation on permeability variations. In fact, adsorbed gas saturation controls which effect will affect the permeability variation in the different production stages according to the development of unsaturated CBM reservoirs (Fig. 1). Additionally, almost no models take the Klinkenberg effect into consideration for describing permeability variation in CBM reservoirs, which are typical low-permeability reservoirs. 
TABLE 1

List of the three most widely used coalbed permeability models

\begin{tabular}{c|c|c}
\hline Authors & Permeability equation & Notes \\
\hline Seidle et al. (1992) [4] & $k=k_{i} \exp \left(-3 c_{f}\left(\sigma-\sigma_{i}\right)\right)$ & Effective stress effect only \\
\hline Seidle and Huitt (1995) [23] & $k=k_{i}\left(1+\left(1+\frac{2}{\varphi_{i}}\right) \varepsilon\left[\frac{p_{i}}{p_{i}+P_{L}}-\frac{p}{p+P_{L}}\right]\right)^{3}$ & Matrix shrinkage effect only \\
\hline $\begin{array}{c}\text { Palmer and Mansoori (1996, 1998) } \\
{[24,25]}\end{array}$ & $k=k_{i}\left(1+\frac{c_{m}}{\varphi_{i}}\left(p-p_{i}\right)+\left(\frac{K}{M}-1\right) \frac{\varepsilon_{l}}{\varphi_{i}}\left[\frac{p_{i}}{p_{i}+P_{L}}-\frac{p}{p+P_{L}}\right]\right)^{3}$ & $\begin{array}{c}\text { Derived from a rock mechanic } \\
\text { approach }\end{array}$ \\
\hline $\begin{array}{c}\text { Shi and Durucan (2004, 2005) } \\
{[26,28]}\end{array}$ & $k=k_{i} \exp \left(3 c_{f}\left(\frac{v}{1-v}\left(p-p_{i}\right)-\frac{E}{3(1-v)} \varepsilon_{l}\left[\frac{p_{i}}{p_{i}+P_{L}}-\frac{p}{p+P_{L}}\right]\right)\right)$ & $\begin{array}{c}\text { Uniaxial strain and constant } \\
\text { vertical stress conditions }\end{array}$ \\
\hline
\end{tabular}

\subsection{Improved Permeability Models above the Critical Desorption Pressure}

During the recovery of unsaturated CBM reservoirs, it is indispensable to dewater the coalbed to release the reservoir pressure. CBM never desorbs from the matrix before the reservoir pressure is reduced to the critical desorption pressure. Permeability variation is controlled by the effective stress effect, rather than the matrix shrinkage or the Klinkenberg effect. Thus, the models of permeability variation during this process must exclude the impact of matrix shrinkage and the Klinkenberg effect.

As a result, the mathematical form of the PM model at this stage can be converted to the following form:

$$
\frac{k}{k_{i}}=\left[1+c_{m}\left(\frac{p-p_{i}}{\varphi_{i}}\right)\right]^{3}
$$

where $k$ is the reservoir permeability at the pressure of $p$, $\mathrm{mD} ; k_{i}$ is the initial reservoir permeability, $\mathrm{mD} ; c_{m}$ is the coal compressibility, $1 / \mathrm{MPa} ; \varphi_{i}$ is the initial porosity, dimensionless; $p_{i}$ is the initial reservoir pressure, MPa.

Likewise, the mathematical form of the SD model is also converted to the following form:

$$
\frac{k}{k_{i}}=\exp \left[3 c_{f} \frac{\vartheta}{1-\vartheta}\left(p-p_{i}\right)\right]
$$

where $\vartheta$ is the Poisson's ratio, dimensionless; $c_{f}$ is the cleat volume compressibility, $1 / \mathrm{MPa}$.

Seidle et al.'s model (1992) [4], which only considered the effect of stress on permeability, is adapted for this single-phase dewatering stage:

$$
\begin{aligned}
& \frac{k}{k_{i}}=\exp \left[-3 c_{f}\left(\sigma_{h 2}-\sigma_{h 1}\right)\right] \\
& \sigma_{h 2}-\sigma_{h 1}=\frac{1}{3} \frac{1+\vartheta}{1-\vartheta}\left(p-p_{i}\right)
\end{aligned}
$$

where $\sigma_{h 1}$ or $\sigma_{h 2}$ is the stress in the $h 1$ or $h 2$ direction, MPa.

\subsection{Improved Permeability Models below the Critical Desorption Pressure}

Once the reservoir pressure has decreased to the critical desorption pressure, the coal matrix starts to shrink due to the desorption of adsorbed CBM from the internal surface of the coal matrix, and additionally the Klinkenberg effect begins to take effect during the seepage flow of free gas in the ultra-low permeable coalbeds. These two effects may eventually counteract the effective stress effect and lead to an increase in permeability. Thus, the models of permeability variation during this process include not only the effective stress effect, but also the matrix shrinkage effect and the Klinkenberg effect.

As a result, the mathematical form of the PM model at this stage should be converted to the following form:

$$
\begin{aligned}
\frac{k}{k_{i}}= & \frac{\left(1+\frac{b}{p}\right)}{\left(1+\frac{b_{c}}{p_{c}}\right)}\left[1+c_{m}\left(\frac{p-p_{i}}{\varphi_{i}}\right)\right. \\
& \left.+\frac{\varepsilon_{l}}{\varphi_{c}}\left(\frac{K}{M}-1\right)\left(\frac{p_{c}}{P_{L}+p_{c}}-\frac{p}{P_{L}+p}\right)\right]^{3}
\end{aligned}
$$

where $b$ is the Klinkenberg coefficient, $\mathrm{MPa} ; b_{c}$ is the Klinkenberg coefficient at the critical desorption pressure, $\mathrm{MPa}$; $p_{c}$ is the critical desorption pressure, $\mathrm{MPa} ; \varepsilon_{l}$ is the Langmuir-type matrix shrinkage constant, dimensionless; $\varphi_{c}$ is the porosity at the critical desorption pressure, dimensionless; $K$ is the bulk modulus, MPa; $M$ is the constrained axial modulus, MPa.

Similarly, the mathematical form of the SD model for the gas-producing stage is converted to 
the following form:

$$
\begin{aligned}
\frac{k}{k_{i}}= & \frac{\left(1+\frac{b}{P}\right)}{\left(1+\frac{b_{c}}{P_{c}}\right)} \exp \left[-3 c_{f}\right. \\
& \left.\times\left[-\frac{\vartheta}{1-\vartheta}\left(p-p_{i}\right)+\frac{E}{3(1-\vartheta)} \varepsilon_{l}\left(\frac{p_{c}}{P_{L}+p_{c}}-\frac{p}{P_{L}+p}\right)\right]\right]
\end{aligned}
$$

Additionally, the Seidle et al.'s model, which only considers the matrix shrinkage, can be used to compare the above two models:

$$
\frac{k}{k_{i}}=\frac{\left(1+\frac{b}{P}\right)}{\left(1+\frac{b_{c}}{P_{c}}\right)}\left[1+\left(1+\frac{2}{\varphi_{c}}\right) \varepsilon_{l}\left(\frac{p_{c}}{P_{L}+p_{c}}-\frac{p}{P_{L}+p}\right)\right]^{3}
$$

\section{RESULTS AND DISCUSSION}

\subsection{Comparisons of the Improved Models with the Original Ones}

The essence of the improved models is piecewise functions with the boundary of the critical desorption pressure to describe permeability variations of unsaturated CBM reservoirs, which is different from the original models. Permeability variations are controlled only by the effective stress effect when the reservoir pressure is above the critical desorption pressure, while its variations are controlled not only by the effective stress effect but also by the matrix shrinkage effect and the Klinkenberg effect when the reservoir pressure is below the critical desorption pressure. In order to distinguish the differences among the new models and the original ones, some work was carried out based on the same input parameters. The major parameters of the coal reservoirs used in the previous studies and chosen for our study are summarized in Table 2.

A plot of the differences in the original and improved PM and SD models for a coalbed reservoir with the same parameters is shown in Figure 2. On the onset of production, the permeability calculated from the improved PM and SD models decreases with the depletion of reservoir pressure. Once reservoir pressure decreases below the critical desorption pressure, the permeability simulated by the improved PM and SD models does not decrease again and maintains a low value. However, since the reservoir pressure further decreases, permeability starts to rebound. Obviously, the rebound rate of permeability in the improved PM model is smaller than that in the SH model, which the rate in the improved SD model approaches. However, in the rebound process, the rate under high pressure in the improved SD model is a bit lower than that in the SH model and the rate under low pressure is a bit higher than that in the SH model. The reason for the difference in those two models is that the

\begin{tabular}{|c|c|c|}
\hline Parameters & Previous values & $\begin{array}{l}\text { Values for } \\
\text { this study }\end{array}$ \\
\hline $\begin{array}{l}\text { Langmuir volume }\left(V_{L}\right), \\
\qquad\left(\mathrm{m}^{3} / \mathrm{t}\right)\end{array}$ & - & 30 \\
\hline $\begin{array}{l}\text { Langmuir pressure }\left(P_{L}\right), \\
\qquad(\mathrm{MPa})\end{array}$ & - & 2 \\
\hline Gas content $(v),\left(\mathrm{m}^{3} / \mathrm{t}\right)$ & - & 20 \\
\hline $\begin{array}{l}\text { Initial reservoir pressure } \\
\qquad\left(p_{i}\right),(\mathrm{MPa})\end{array}$ & - & 8 \\
\hline $\begin{array}{c}\text { Cleat volume } \\
\text { compressibility }\left(c_{f}\right),\left(\mathrm{MPa}^{-1)}\right.\end{array}$ & $0.14[27]$ & 0.140 \\
\hline $\begin{array}{l}\text { Initial cleat porosity }\left(\varphi_{i}\right), \\
\text { (dimensionless) }\end{array}$ & $\begin{array}{c}0.001 \sim 0.06[68] \\
0.01 \sim 0.05[69]\end{array}$ & 0.008 \\
\hline Poisson (v), (dimensionless) & $\begin{array}{l}0.35[27] \\
0.39[70]\end{array}$ & 0.35 \\
\hline Young's modulus (E), (MPa) & $\begin{array}{c}2900[27] \\
2070 \sim 4140[13]\end{array}$ & 3000 \\
\hline $\begin{array}{c}\text { Langmuir curve-match for } \\
\text { shrinkage }\left(\varepsilon_{l}\right) \\
\text { (dimensionless) }\end{array}$ & $\begin{array}{c}0.00507 \sim 0.04389[71] \\
0.01264[72] \\
0.00754[13] \\
0.01075[39]\end{array}$ & 0.008 \\
\hline $\begin{array}{c}\text { Klinkenberg coefficient }(b), \\
\text { (MPa) } \\
b_{c}=2 b\end{array}$ & $\begin{array}{c}\sim 0.0528 \text { for } 1 \mathrm{mD}[73] \\
\sim 0.1269 \text { for } 0.1 \mathrm{mD}[73] \\
\sim 0.3050 \text { for } 0.01 \mathrm{mD}[73] \\
\sim 0.7334 \text { for } 0.001 \mathrm{mD}[73]\end{array}$ & 0.15 \\
\hline
\end{tabular}

TABLE 2

Summary of parameters and their values used in the models

SH model only considers the matrix shrinkage effect and the improved SD model considers not only the matrix shrinkage effect but also the effective stress effect and the Klinkenberg effect. Permeability simulated in the original PM and SD models decreases only slightly with depletion of pressure, which cannot reflect the only impact of the effective stress effect in the initial recovery stage of unsaturated CBM reservoirs, because those original models also consider the impact of the matrix shrinkage effect on permeability, which conflicts with the initial production performance of unsaturated CBM reservoirs.

\subsection{Sensitivity Analysis of the Improved Permeability Models}

\subsubsection{Gas Content}

Gas content determines gas saturation, affecting the critical desorption pressure in coal reservoirs with similar reservoir pressure and isothermal adsorption properties. A slight unsaturation can necessitate prolonging the dewatering time [57]. 

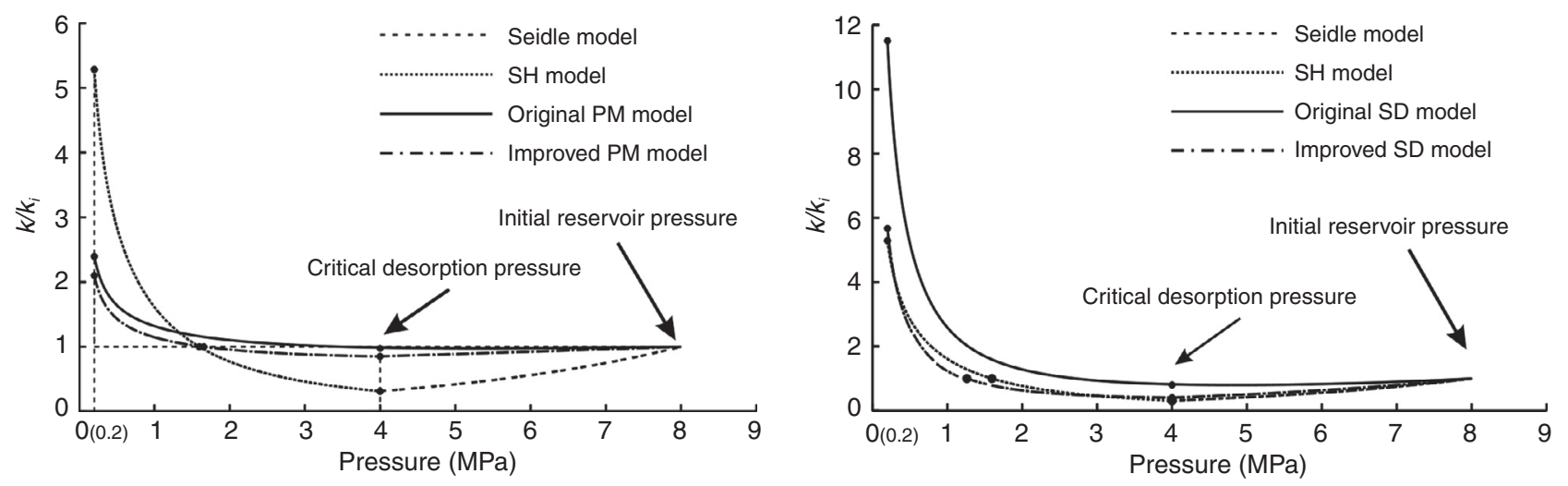

Figure 2

Comparisons of the original and improved models.
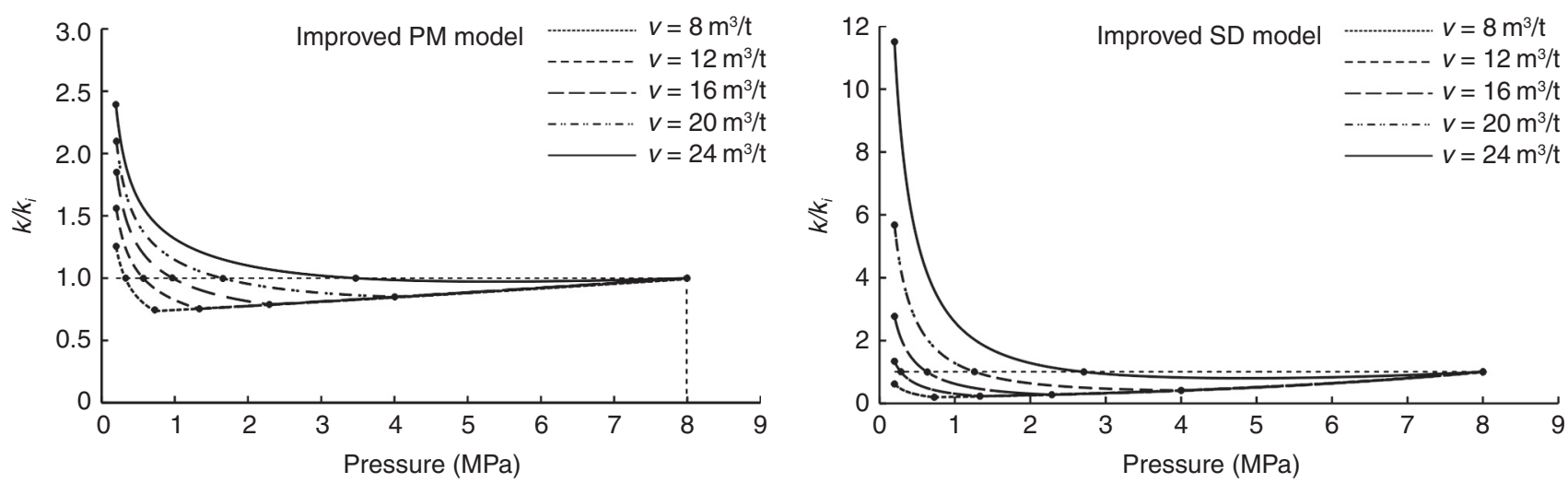

Figure 3

Sensitivity analysis of the improved permeability variation models with gas content.

The dynamic variation of coal seam permeability and its rebound effect are obviously affected by gas content/gas saturation in Figure 3. In the case of the similar other parameters, both the improved PM and SD models with gas content of $8,12,16$ and $20 \mathrm{~m}^{3} / \mathrm{t}$ show that coal seam permeability is damaged only by effective stress in the dewatering stage. The lower the gas content, the more serious the damage of permeability caused by effective stress and the poorer the rebound effect in the late gas-producing stage. If gas content in the coal seam is $24 \mathrm{~m}^{3} / \mathrm{t}$, in other words, gas saturation reaches $100 \%$, permeability does not cause damage or improve significantly in a long time of the initial recovery, because it is affected comprehensively both by the effective stress and coal matrix shrinkage effect. Until the reservoir pressure is further reduced, permeability starts to improve significantly. Overall, high gas content highlights permeability rebound by matrix shrinkage and suppresses permeability damage by effective stress. The sensitivity of various gas contents to permeability in the improved SD model is stronger than that in the improved PM model.

\subsubsection{Initial Reservoir Pressure}

The characteristic of permeability dynamic variation caused by the initial reservoir pressure in the recovery of unsaturated CBM reservoirs is shown in Figure 4. In the conditions of similar other parameters, both the improved PM model and SD models with initial reservoir pressure of $6,8,10$ and $12 \mathrm{MPa}$ show that coal reservoir permeability is damaged only by effective stress. The larger the initial reservoir pressure, the more serious the permeability damage and the poorer rebound effect in the late production stage. 

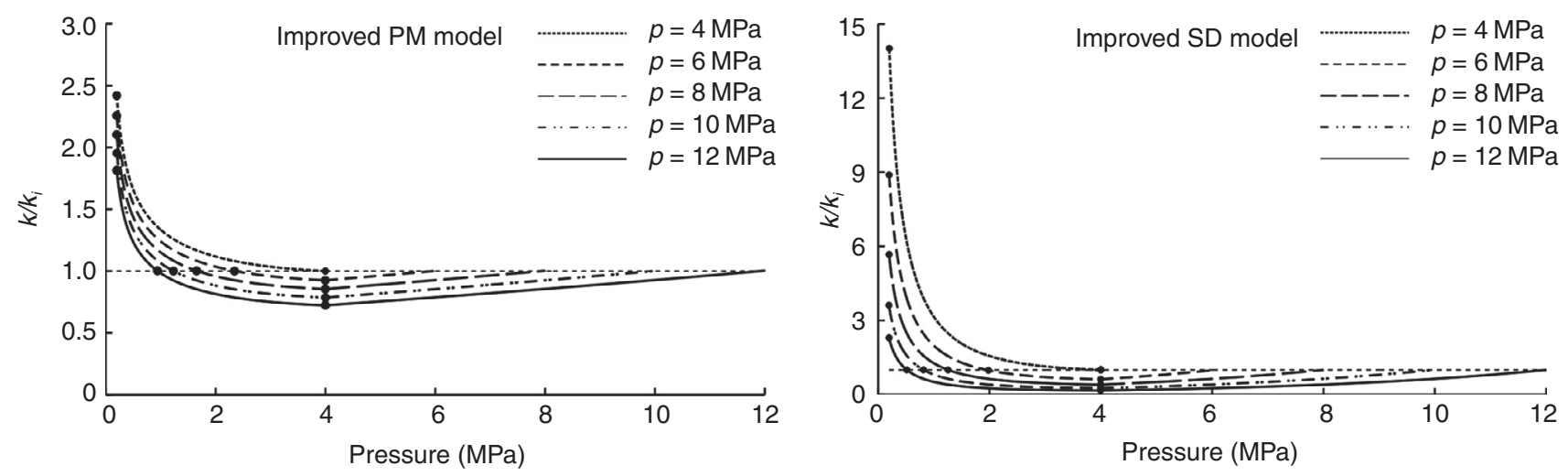

Figure 4

Sensitivity analysis of the improved permeability variation models with reservoir pressure.
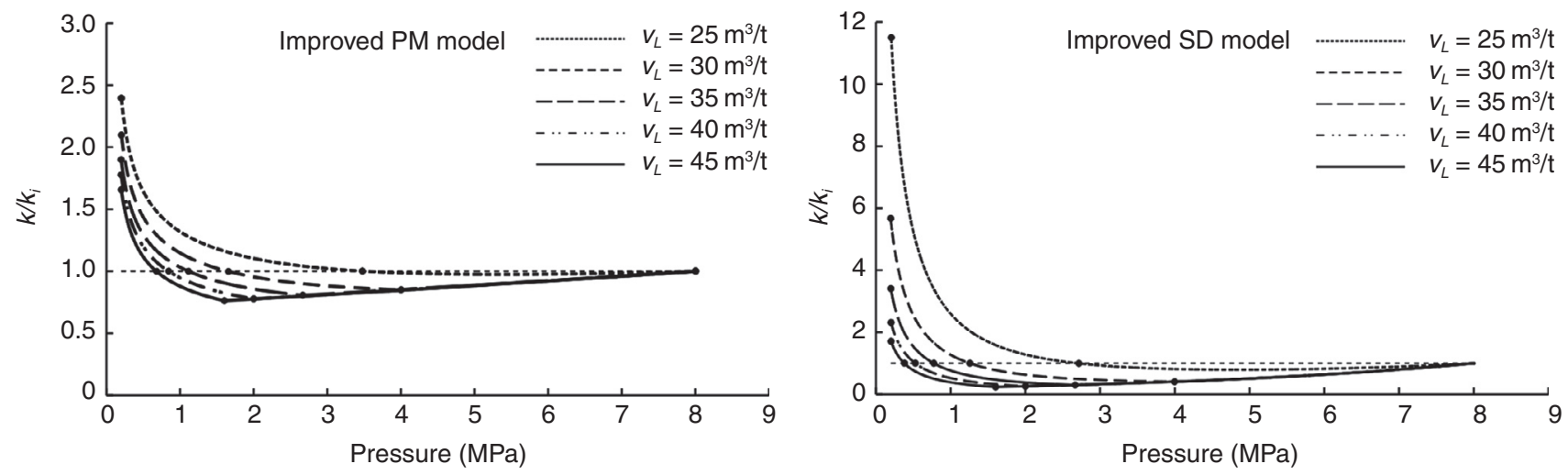

Figure 5

Sensitivity analysis of the improved permeability variation models with Langmuir volume.

The main reason of this phenomenon is that coal seam adsorption ability was controlled by initial coal reservoir pressure under the same other parameters. The higher the initial coal pressure, the greater the adsorption capacity. Therefore, gas saturation in a coal seam with high coal reservoir pressure is obviously low even with the same gas content. Permeability with low gas saturation is often seriously damaged by effective stress in the dewatering stage, which leads to an insignificant rebound of permeability in the late production stage. However, permeability with an initial coal reservoir pressure of $4 \mathrm{MPa}$ (namely, gas saturation of $100 \%$ ) is almost unaffected by effective stress, and shows that the impact of the coal matrix shrinkage effect and Klinkenberg effect on permeability exceeds that of the effective stress effect. A comparative study proves the sensitivity of the initial coal reservoir pressure to permeability in the improved SD model is greater than that in the improved PM model.

\subsubsection{Langmuir Parameters of Adsorption}

The coal seam has a strong physical adsorption capacity, and it is usually characterized by the isothermal adsorption curve. During the recovery of CBM reservoirs, CBM is desorbed from the inner face of pores in the coal seam by reducing pressure, which causes coal matrix shrinkage. This shrinkage is the main effect causing the increase in coal permeability with the depletion of pressure. The influences of the Langmuir volume and Langmuir pressure on unsaturated CBM reservoirs' permeability variation are shown in Figures 5 and 6.

The difference in coal reservoir permeability dynamic variation is obvious among Langmuir volumes from 25 to $45 \mathrm{~m}^{3} / \mathrm{t}$, especially in the improved SD model. In general, in the case of the same other parameters, the larger the Langmuir volume, the smaller the gas saturation, and the longer the dewatering stage at the same depressurization rate. Therefore, under the same conditions, a large Langmuir 

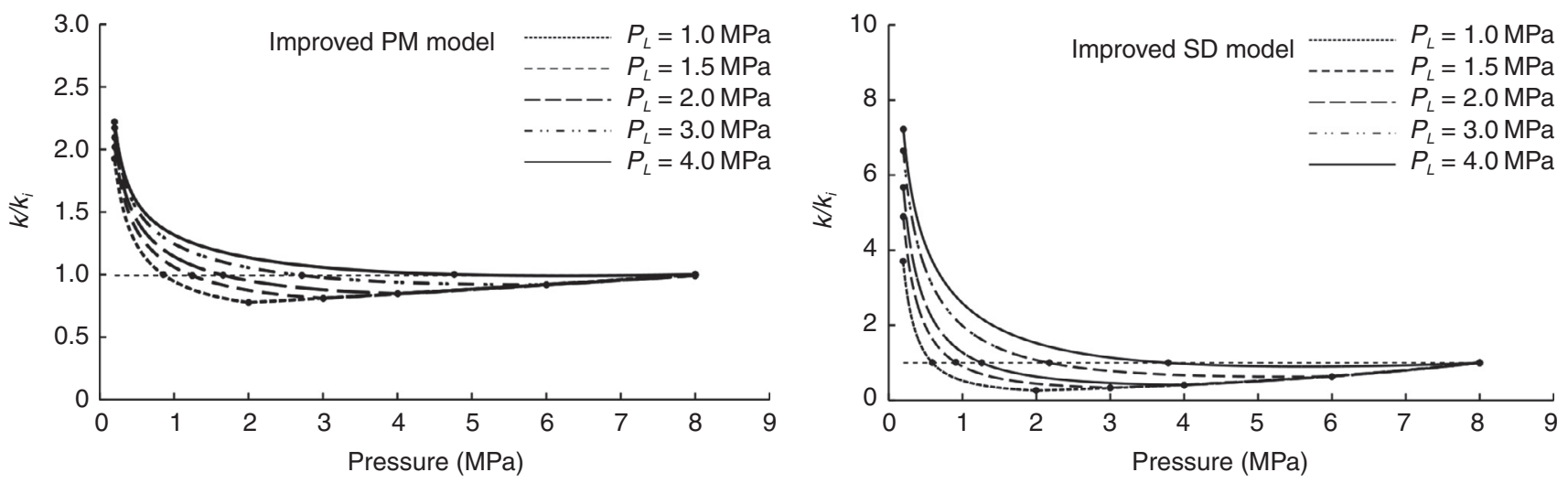

Figure 6

Sensitivity analysis of the improved permeability variation models with Langmuir pressure.
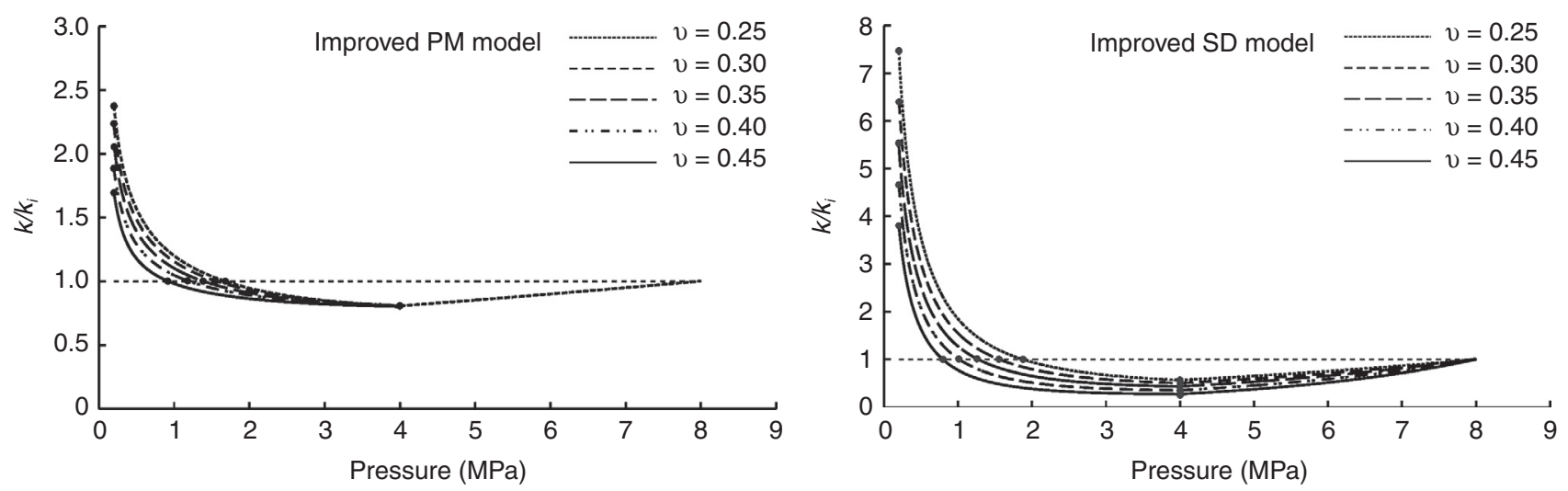

Figure 7

Sensitivity analysis of the improved permeability variation models with Poisson's ratio.

volume is apt to damage permeability by effective stress in the dewatering stage, which is unfavorable for permeability rebound in the late production stage. Coal permeability dynamic variation is also influenced by the Langmuir pressure. In the improved PM model, permeability dynamic variation caused by various Langmuir pressures is obvious in the middle production stage, but permeability remains almost the same in the end with reservoir pressure of $0.2 \mathrm{MPa}$. In the improved SD model, permeability with a Langmuir pressure of $4 \mathrm{MPa}$ is approximately twice that with a Langmuir pressure of $1 \mathrm{MPa}$ when the reservoir pressure drops to $0.2 \mathrm{MPa}$.

\subsubsection{Poisson's Ratio}

Poisson's ratio refers to the ratio of a material's transverse strain and longitudinal strain. As the cleats growing perpendicularly to the horizontal bedding are main flow channels, the increase in effective stress results in the lateral strain increasing and the cleat fissure gradually narrowing during the depletion of pressure, and finally causes permeability reduction. A plot of the impact of various Poisson's ratios on dynamic variation of permeability is shown in Figure 7. In the improved PM model, Poisson's ratio does not take effect in the stage of permeability damage because Equation (2) does not contain Poisson's ratio. Once the reservoir pressure is below the critical desorption pressure, the increase in permeability at high Poisson's ratio is always less than that at low Poisson's ratio. In the improved SD model, the higher the Poisson's ratio, the greater the damage of effective stress, and finally, the worse the ultimate rebound of permeability. At the same time, the ultimate permeability at 0.25 Poisson's ratio is about twice as much as the permeability at 0.45 . 

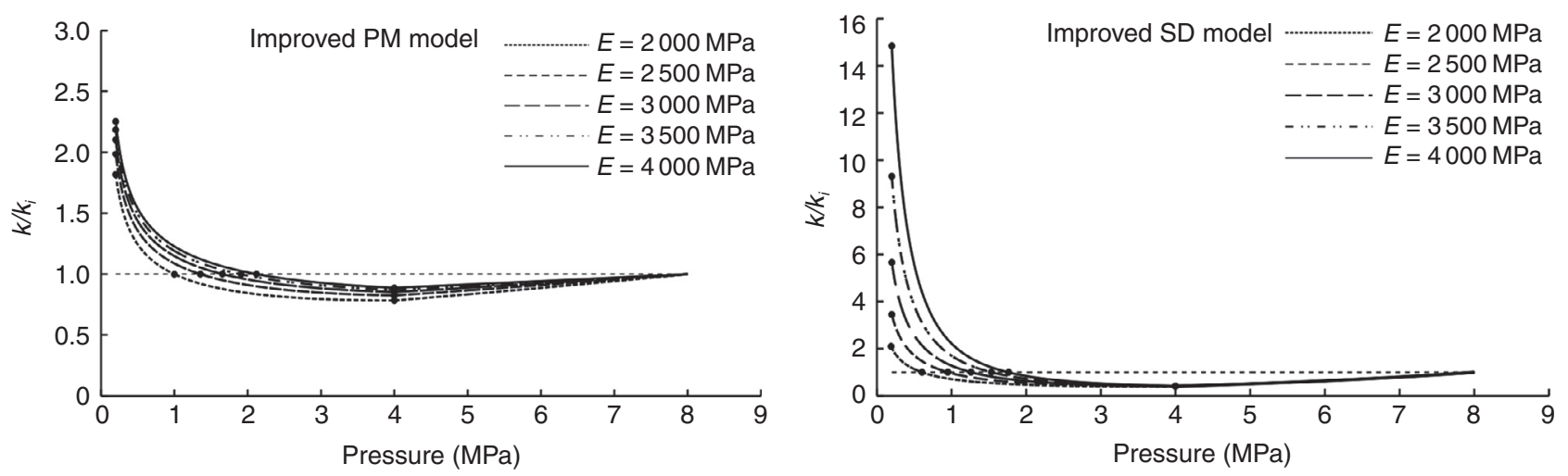

Figure 8

Sensitivity analysis of the improved permeability variation models with Young's modulus.

\subsubsection{Young's Modulus}

Young's modulus is one of the most important mechanics parameters in coal permeability. In order to compare the effect of Young's modulus on the dynamic variation of permeability in the improved PM and SD models, permeability is calculated under the range of modulus from $2000 \mathrm{MPa}$ to $4000 \mathrm{MPa}$ (Fig. 8). Because of the differences between introduction of Young's modulus into the improved PM and SD models, dynamic variation of permeability is obviously different in those two improved models. In the improved PM model, permeability in the whole CBM production process is affected by Young's modulus, but the impact of Young's modulus from $2000 \mathrm{MPa}$ to $4000 \mathrm{MPa}$ on the dynamic variation of permeability is limited, especially at the initial stage of recovery. In the improved SD model, the dynamic variation of permeability is slightly affected by Young's modulus when the reservoir pressure is greater than the critical desorption pressure, while it is obviously affected when the reservoir pressure is smaller than the critical desorption pressure. The ultimate improved permeability at $4000 \mathrm{MPa}$ is more than 7 times that at $2000 \mathrm{MPa}$ in the improved SD model, indicating that the impact of Young's modulus on permeability increases as the reservoir pressure decreases gradually.

\subsubsection{Langmuir Curve-Match for Shrinkage Coefficient}

The swelling/shrinkage behavior in coal due to gas adsorption/desorption follows the same form as the Langmuir isotherm, thus explained by a Langmuir-like equation $[12,13$, 30]. Since Levine (1996) [13] used a Langmuir form of equation to describe the swelling and achieved good agreement with the experimental measurements, many authors have applied the Langmuir curve-match for shrinkage coefficient to describe the effect of matrix shrinkage on permeability variation [25-27]. In this study, a series of Langmuir curve-match for shrinkage coefficients ranging from 0.004 to 0.020 were applied to calculate the dynamic variation of coalbed reservoirs in the improved PM and SD models (Fig. 9). Shown in Figure 9, these parameters do not lead to dynamic variation of permeability before reservoir pressure decreases to the critical desorption pressure. These parameters start to take effect after the reservoir pressure decreases and reaches the critical desorption pressure and then plays a more and more significant role in permeability variation when the pressure continues to decrease. The ultimate permeability with a shrinkage coefficient of 0.020 is 2.5 times that of permeability with a shrinkage coefficient of 0.004 in the improved PM model. The ultimate permeability with a shrinkage coefficient of 0.012 is 2.5 times that of permeability with shrinkage coefficient of 0.004 in the improved SD model. It indicates that the shrinkage coefficient is an important factor affecting permeability variation as the reservoir pressure decreases.

\subsubsection{Klinkenberg Coefficient}

The Klinkenberg effect is very obvious in reservoirs with low porosity and low permeability, which is rarely considered in permeability models, even though a coal reservoir is a typical low poro-perm reservoir. In this paper, in order to analyze the characteristics of permeability variation in low-porosity and low-permeability coal reservoirs, the Klinkenberg effect is cited in the improved PM and SD models. According to the study of Tanikawa and Shimamoto (2006) [73], Klinkenberg coefficient $b$ is closely related to the magnitude of permeability and it doubles as the magnitude of permeability decreases each time, which is listed in Table 2. 

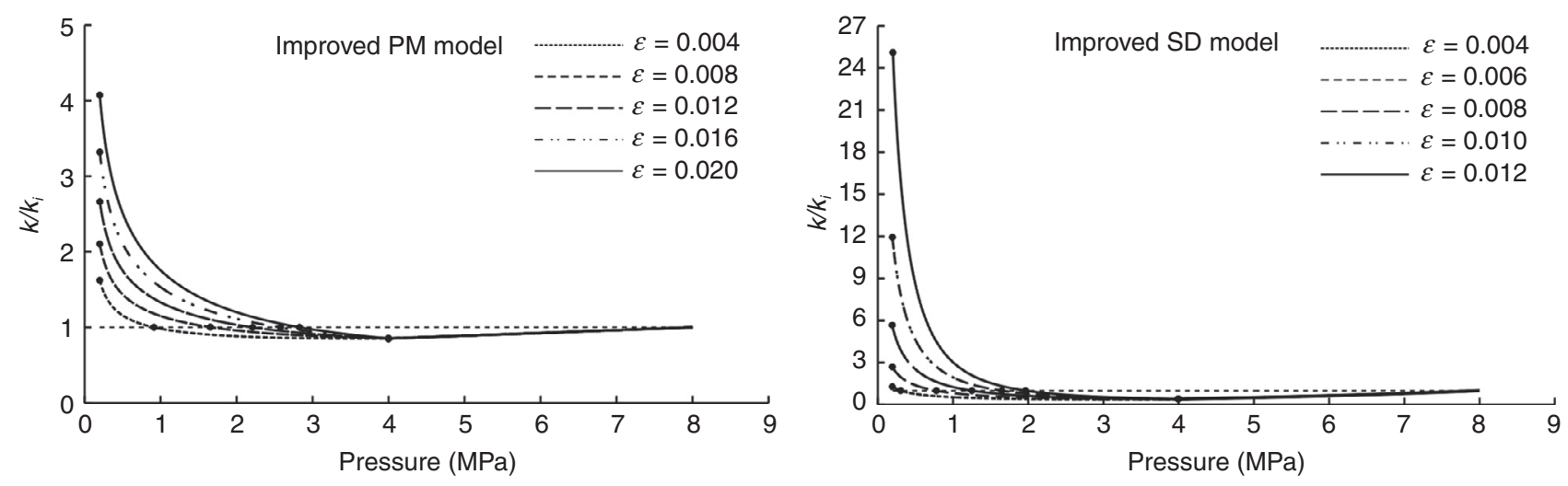

Figure 9

Sensitivity analysis of the improved permeability variation models with the shrinkage coefficient.
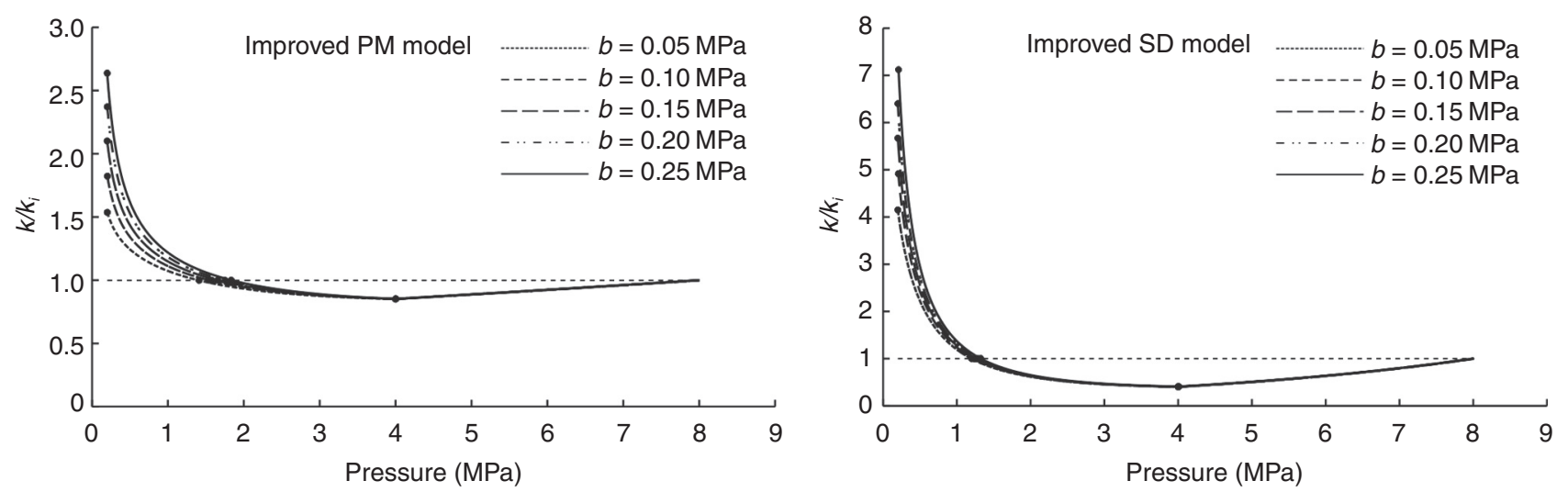

Figure 10

Sensitivity analysis of the improved permeability variation models with the Klinkenberg coefficient.

Thus, the Klinkenberg coefficient at the critical desorption pressure $\left(b_{c}\right)$ was twice the Klinkenberg coefficient $b$ in our paper. Before a CBM reservoir's pressure drops to its critical desorption pressure, especially when the CBM has not been desorbed, the Klinkenberg effect does not exist because there is no flow of gas. The permeability is affected slightly by the Klinkenberg effect most of the time after dropping below the critical desorption pressure. Only when the reservoir pressure drops to $1.5 \mathrm{MPa}$ does the Klinkenberg effect begin to take effect and is highlighted with the decreasing reservoir pressure. From Figure 10, the impact of the Klinkenberg effect on permeability shows no difference between the improved PM model and the improved SD model, which can also be reflected in the formulae of these two models. Reservoir permeability with a slippage coefficient of $0.25 \mathrm{MPa}$ is approximately 1.8 times that with a slippage coefficient of $0.05 \mathrm{MPa}$.

\section{CONCLUSIONS}

Associating the existing permeability variation models with the production performance of unsaturated CBM reservoirs, the improved PM and SD models are established by considering the Klinkenberg effect. The improved models are much more suitable than the original models for describing permeability dynamic variation of unsaturated CBM reservoirs due to gas unsaturation. Sensitivity analysis of various parameters on permeability variation show that these parameters, including the gas content, reservoir pressure, Langmuir volume, Langmuir pressure, Poisson's ratio, Young's modulus, shrinkage coefficient and Klinkenberg coefficient have a significant impact on permeability variation of unsaturated CBM reservoirs. These parameters show obvious different impacts on permeability variation at different production stages. The gas content, reservoir pressure, 
Langmuir volume and Langmuir pressure have an impressive impact on permeability variation in the first stage in which the reservoir pressure decreases but does not reach critical adsorption pressure. Except for the above-mentioned parameters, Poisson's ratio, Young's modulus and the shrinkage coefficient have a significant impact in the second stage in which the reservoir pressure is depleted below the critical adsorption pressure. A comparative study of the improved PM and SD models indicates the improved SD model has a greater sensitivity to various parameters than the improved PM model.

\section{ACKNOWLEDGMENTS}

This work was financially supported by the Key Project of the National Science \& Technology Pillar Program (Grant No. 2011ZX05038-001), the National Natural Science Foundation Project (41272175) and the China Postdoctoral Science Foundation-funded project (2014M561020).

\section{REFERENCES}

1 Somerton W.H., Söylemezoglu I.M., Dudley R.C. (1975) Effect of stress on permeability of coal, International Journal of Rock Mechanics and Mining Sciences \& Geomechanics Abstracts 12, 5-6, 129-145.

2 Durucan S., Edwards J.S. (1986) The Effect of stress and fracturing on permeability of coal, Mining Science and Technology 3, 205-216.

3 McKee C.R., Bumb A.C., Koenig R.A. (1987) Stressdependent permeability and porosity of coal, Proceedings of the 1987 Coalbed Methane Symposium, Tuscaloosa, Alabama, pp. 183-190.

4 Seidle J.P., Jeansonne M.W., Erickson D.J. (1992) Application of matchstick geometry to stress dependent permeability in coals, Rocky Mountain Regional Meeting of the Society of Petroleum Engineers, Casper, Wyoming, 18-21 May, SPE 24361.

5 Connell L.D., Lu M., Pan Z. (2010) An analytical coal permeability model for tri-axial strain and stress conditions, International Journal of Coal Geology 84, 2, 103-114.

6 Connell L.D., Pan Z., Lu M., Heryanto D., Camilleri M. (2010) Coal permeability and its behavior with gas desorption, pressure and stress, SPE Asia Pacific Oil \& Gas Conference and Exhibition, Brisbane, Australia, 18-20 Oct., SPE Paper 133915.

7 Jasinge D., Ranjith P.G., Choi S.K. (2010) Effects of effective stress changes on permeability of latrobe valley brown coal, Fuel 90, 1292-1300.

8 Harpalani S., Zhao X. (1989) An investigation of the effect of gas desorption on coal permeability formation, Proceedings of the 1989 Coalbed Methane Symposium, Tuscaloosa, Alabama, pp. 57-64.

9 Harpalani S., Schraufnagel R.A. (1990) Shrinkage of coal matrix with release of gas and its impact on permeability of coal, Fuel 69, 551-556.
10 Harpalani S., Chen G.L. (1997) Influence of gas production induced volumetric strain on permeability of coal, Geotechnical and Geological Engineering 15, 4, 303-325.

11 Bodden W.P., Ehrlich R. (1998) Permeability of coals and characteristics of desorption tests: Implications for coalbed methane production, International Journal of Coal Geology 35, 333-347.

12 Chikatamarla L., Cui X., Bustin R.M. (2004) Implications of volumetric swelling/shrinkage of coal in sequestration of acid gases, Proceedings of the 2004 Coalbed Methane Symposium, Tuscaloosa, Alabama.

13 Levine J.R. (1996) Model study of the influence of matrix shrinkage on absolute permeability of coal bed reservoirs, in Coalbed Methane and Coal Geology, Gayer R., Harris I. (eds), Geological Society Special Publication, 109, London, pp. 197-212.

14 Robertson E.P., Christiansen R.L. (2006) A permeability model for coal and other fractured, sorptive-elastic media, SPE Eastern Regional Meeting, Society of Petroleum Engineers, Society of Petroleum Engineers, Canton, Ohio, USA.

15 Pan Z., Connell L.D. (2007) A theoretical model for gas adsorption-induced coal swelling, International Journal of Coal Geology 69, 243-252.

16 Viete D.R., Ranjith P.G. (2007) The mechanical behavior of coal with respect to $\mathrm{CO}_{2}$ sequestration in deep coal seams, Fuel 86, 2667-2671.

17 Lin W., Tang G.-Q., Kovscek A.R. (2008) Sorption-induced permeability change of coal during gas-injection processes, SPE Reservoir Evaluation \& Engineering 11.

18 Balan H.O., Gumrah F. (2009) Assessment of shrinkage-swelling influences in coal seams using rank-dependent physical coal properties, International Journal of Coal Geology 77, 203-213.

19 Clarkson C.R., Pan Z., Palmer I.D., Harpalani S. (2010) Predicting sorption-induced strain and permeability increase with depletion for coalbed-methane reservoirs, SPE Journal 15, 1, 152-159.

20 Zhu W.C., Liu J., Sheng J.C., Elsworth D. (2007) Analysis of coupled gas flow and deformation process with desorption and Klinkenberg effects in coal seams, Journal of Rock Mechanics and Mining Sciences 44, 971-980.

21 Gray I. (1987) Reservoir engineering in coal seams, part 1-the physical process of gas storage and movement in coal seams, SPE Reservoir Engineering 2, 1, 28-34.

22 Sawyer W.K., Zuber M.D., Kuuskraa V.A. (1987) Using reservoir simulation and field data to define mechanisms controlling coalbed methane production, Proceedings of the 1987 Coalbed Methane Symposium, Alabama, 295-307.

23 Seidle J.R., Huitt L.G. (1995) Experimental measurement of coal matrix shrinkage due to gas desorption and implications for cleat permeability increases, International Meeting on Petroleum Engineering, Beijing, China.

24 Palmer I., Mansoori J. (1996) How permeability depends on stress and pore pressure in coalbeds, a new model, SPE Annual Technical Conference and Exhibition, Denver, Colorado.

25 Palmer I., Mansoori J. (1998) Permeability depends on stress and pore pressure in coalbeds, a new model, SPE Reservoir Evaluation and Engineering 1, 6, 539-544.

26 Shi J.Q., Durucan S. (2004) Drawdown induced changes in permeability of coalbeds: a new interpretation of the reservoir response to primary recovery, Transport in Porous Media 56, $1-16$. 
27 Shi J.Q., Durucan S. (2004) A numerical simulation study of the Allison Unit $\mathrm{CO}_{2}-$ ECBM pilot: the effect of matrix shrinkage and swelling on ECBM production and $\mathrm{CO}_{2}$ injectivity, Proceedings of the 7th International Conference on Greenhouse Gas Control Technologies, Sept. 5-9, Vancouver, Canada 1, 431-442.

28 Shi J.Q., Durucan S. (2005) A model for changes in coalbed permeability during primary and enhanced methane recovery, SPE Reservoir Evaluation and Engineering 8, 4, 291-299.

29 Zhao Y., Hu Y., Wei J., Yang D. (2003) The experimental approach to effective stress law of coal mass by effect of methane, Transport in Porous Media 53, 3, 235-244.

30 Cui X., Bustin R.M. (2005) Volumetric strain associated with methane desorption and its impact on coalbed gas production from deep coal seams, AAPG Bulletin 89, 9, 1181-1202.

31 Cui X., Bustin R.M., Chikatamarla L. (2007) Adsorptioninduced coal swelling and stress, implications for methane production and acid gas sequestration into coal seams, Journal of Geophysical Research-Solid Earth 112, B10202.

32 Gu F., Chalaturnyk R.J. (2006) Numerical simulation of stress and strain due to gas sorption/desorption and their effects on in situ permeability of coalbeds, Journal of Petroleum Science and Engineering 45, 10, 52-62.

33 Gu F., Chalaturnyk R.J. (2010) Permeability and porosity models considering anisotropy and discontinuity of coalbeds and application in coupled simulation, Journal of Petroleum Science and Engineering 74, 3-4, 113-131.

34 Connell L.D. (2009) Coupled flow and geomechanical processes during gas production from coal seams, International Journal of Coal Geology 79, 1-2, 18-28.

35 Connell L.D., Detournay C. (2009) Coupled flow and geomechanical processes during enhanced coal seam methane recovery through $\mathrm{CO}_{2}$ sequestration, International Journal of Coal Geology 77, 1-2, 222-233.

36 Wang G.X., Massarotto P., Rudolph V. (2009) An improved permeability model of coal for coalbed methane recovery and $\mathrm{CO}_{2}$ geosequestration, International Journal of Coal Geology 77, 1-2, 127-136.

37 Liu H.H., Rutqvist J. (2010) A new coal-permeability model, internal swelling stress and fracture-matrix interaction, Transport in Porous Media 82, 1, 157-171.

38 Liu J., Chen Z., Elsworth D., Miao X.X., Mao X.B. (2010) Linking gas-sorption induced changes in coal permeability to directional strains through a modulus reduction ratio, International Journal of Coal Geology 83, 1, 21-30.

39 Liu S., Harpalani S., Mallikarjun P. (2012) Laboratory measurement and modeling of coal permeability with continued methane production: Part 2 - Modeling results, Fuel 94, 117-124.

40 Wu Y., Liu J., Elsworth D., Miao X.X., Mao X.B. (2010) Development of anisotropic permeability during coalbed methane production, Journal of Natural Gas Science and Engineering 2, 4, 197-210.

41 Wei Z., Zhang D. (2010) Coupled fluid-flow and geomechanics for triple-porosity/dual- permeability modeling of coalbed methane recovery, International Journal of Rock Mechanics and Mining Sciences 47, 8, 1242-1253.

42 Izadi G., Wang S., Elsworth D., Liu J., Wu Y., Pone D. (2011) Permeability evolution of fluid-infiltrated coal containing discrete fractures, International Journal of Coal Geology 85, 202-211.
43 Ma Q., Harpalani S., Liu S. (2011) A simplified permeability model for coalbed methane reservoirs based on matchstick strain and constant volume theory, International Journal of Coal Geology 85, 1, 43-48.

44 Pan Z., Connell L.D. (2011) Modelling of anisotropic coal swelling and its impact on permeability behaviour for primary and enhanced coalbed methane recovery, International Journal of Coal Geology 85, 257-267.

45 Rice D.D. (1993) Composition and origins of coalbed gas, $A A P G$ 38, 159-184.

46 Scott A.R. (1993) Composition and origin of coalbed gases from selected basins in the United States, Proceedings of the 1993 Coalbed Methane Symposium, Tuscaloosa, Alabama, pp. 207-222.

47 Scott A.R., Kaiser W.R., Ayers W.B. Jr (1994) Thermogenic and secondary biogenic gases, San Juan Basin, Colorado and New Mexico-implications for coalbed gas producibility, AAPG Bulletin 78, 1186-1209.

48 Scott A.R. (2002) Hydrogeologic factors affecting gas content distribution in coal beds, International Journal of Coal Geology 50, 363-387.

49 Diamond W.P., Schatzel S.J. (1998) Measuring the gas content of coal: a review, International Journal of Coal Geology 35, 311-331.

50 Stricker G.D., Flores R.M. (2002) Coalbed methane content in the Powder River Basin, Wyoming: saturation by coal rank and depth, 2002 International Pittsburgh Coal Conference, Sept. 23-27.

51 Lamarre R. (2006) Under-saturation in coals: How does it happen and why is it important: Search and Discovery Article 40195, Available at: http://www.searchanddiscovery.net/ documents/2006/06034/amarre/index.htm.

52 Bustin A.M.M., Bustin R.M. (2008) Coal reservoir saturation: impact of temperature and pressure, American Association of Petroleum Geologists Bulletin 92, 77-86.

53 Gentzis T., Goodarzi F., Cheung F.K., Laggoun-Défargec F. (2008) Coalbed methane producibility from the Mannville coals in Alberta, Canada: A comparison of two areas, International Journal of Coal Geology 74, 237-249.

54 Mares T.E., Moore T.A., Moore C.R. (2009) Uncertainty of gas saturation estimates in a subbituminous coal seam, International Journal of Coal Geology 77, 320-327.

55 Yao Y.B., Liu D.M., Tang D.Z., Huang W.H. (2009) Preliminary evaluation of the coalbed methane production potential and its geological controls in the Weibei Coalfield, Southeastern Ordos Basin, China, International Journal of Coal Geology 78, 1, 1-15.

56 Yao Y.B., Liu D.M., Qiu Y.K. (2013) Variable gas content, saturation, and accumulation characteristics of Weibei coalbed methane pilot-production field in the southeastern Ordos Basin, China, AAPG Bulletin 97, 8, 1371-1393.

57 Pashin J.C. (2010) Variable gas saturation in coalbed methane reservoirs of the Black Warrior Basin: Implications for exploration and production, International Journal of Coal Geology 82, 135-146.

58 Wong S., Macdonald D., Andrei S., Guntera W.D., Denga X., Lawc D., Yed J., Fengd S., Fand Z., Hoe P. (2010) Conceptual economics of full scale enhanced coalbed methane production and $\mathrm{CO}_{2}$ storage in anthracitic coals at South Qinshui basin, Shanxi, China, International Journal of Coal Geology 82, 280-286. 
59 Ayers W.B. (2002) Coalbed gas systems, resources, and production and a review of contrasting cases from the San Juan and Powder River Basins, AAPG Bulletin 86, 1853-1890.

60 Hamelinck C., Faaij A., Turkenburg W., van Bergen F., Pagnier H.J.M., Barzandji O.H.M., Wolf K.-H.A.A., Ruijg G.J. (2002) $\mathrm{CO}_{2}$ enhanced coalbed methane production in the Netherlands, Energy 27, 7, 647-674.

61 Langmuir I. (1918) The adsorption of gases on plane surfaces of glass, mica and platinum, Journal of the American Chemical Society 40, 1361.

62 Dubinin M.M., Astakhov V.A. (1971) Description of adsorption equilibria of vapors on zeolites over wide ranges of temperature and pressure, Advances in Chemistry 102, 69-85, American Chemical Society Publications, Washington, DC.

63 DeGance A.E. (1992) Multicomponent high-pressure adsorption equilibria on carbon substrates: theory and data, Fluid Phase Equilibria 78, 99-137.

64 Zhou C., Hall F., Gasem K.A.M., Robinson R.L. Jr. (1994) Predicting gas adsorption using two-dimensional equations of state, I\&EC Research 33, 1280-1289.

65 Clarkson C.R., Bustin R.M. (2000) Binary gas adsorption/ desorption isotherms: Effect of moisture and coal composition upon carbon dioxide selectivity over methane, International Journal of Coal Geology 42, 241-271.

66 Fitzgerald J.E., Pan Z., Sudibandriyo M., Robinson R.L. Jr, Gasem K.A.M. (2005) Adsorption of methane, nitrogen, carbon dioxide and their mixtures on wet Tiffany coal, Fuel 84, 2351-2363.

67 Pan Z.J., Connell L.D. (2009) Comparison of adsorption models in reservoir simulation of enhanced coalbed methane recovery and $\mathrm{CO}_{2}$ sequestration in coal, International Journal of Greenhouse Gas Control 3, 77-89.
68 Gas Research Institute (GRI) (2002) A Guide to Coalbed Methane Reservoir Engineering, Report GRI-94/ 0397.

69 Mavor M.J., Gunter W.D. (2004) Secondary porosity and permeability of coal: gas composition and pressure, SPE Annual Technical Conference and Exhibition, Houston, Texas, USA, 26-29 Sept.

70 Jones S.C. (1972) A rapid accurate unsteady-state klinkenberg permeameter, SPE Formation Evaluation 12, 5, 383-397.

71 Zahner B. (1997) Application of material balance to determine ultimate recovery of a San Juan Fruitland coal wel, SPE Annual Technical Conference and Exhibition, 5-8 Oct., San Antonio, Texas, SPE 38858.

72 Mavor M.J., Vaughn J.E. (1998) Increasing coal absolute permeability in the San Juan basin Fruitland formation, SPE Reservoir Evaluation and Engineering 1, 3, 201-206.

73 Tanikawa W., Shimamoto T. (2006) Klinkenberg effect for gas permeability and its comparison to water permeability for porous sedimentary rocks, Hydrology \& Earth System Sciences Discussions 3, 4, 1315-1338.

74 Klinkenberg L.J. (1941) The permeability of porous media to liquids and gases, Drilling and production Practice, American Petroleum Inst., pp. 200-213.
Manuscript submitted in October 2014

Manuscript accepted in March 2015

Published online in August 2015

Cite this article as: Y. Lv, Z. Li, D. Tang, H. Xu and X. Chen (2016). Permeability Variation Models for Unsaturated Coalbed Methane Reservoirs, Oil Gas Sci. Technol 71, 32. 


\section{Appendix: Derivation of the Permeability Variation due to the Klinkenberg Effect}

According to Klinkenberg (1941) [74], effective gas permeability at a finite pressure is given by:

$$
k_{g}=k_{\infty}\left(1+\frac{b}{p}\right)
$$

where $k_{g}$ is the gas phase permeability, $\mathrm{mD} ; k_{\infty}$ is the absolute permeability under very large gas-phase pressure in which conditions the Klinkenberg effects are negligible, $\mathrm{mD}$; and $b$ is the Klinkenberg factor, dependent on the pore structure of the medium and temperature for a given gas, $\mathrm{MPa}$ :

$$
b=\frac{4 C \lambda p}{r}
$$

where $C$ is the proportionality factor, dimensionless; $\lambda$ is the mean free path of gas molecules, m; $r$ is the radius of a capillary or a pore, $\mathrm{m}$.

Permeability variations are due to the Klinkenberg effect when the CBM reservoir pressure varies from $p_{i}$ to $p$ with the depressurization of CBM reservoirs. Thus:

$$
\begin{aligned}
k_{i} & =k_{\infty}\left(1+\frac{b_{i}}{p_{i}}\right) \\
k & =k_{\infty}\left(1+\frac{b}{p}\right)
\end{aligned}
$$

and then,

$$
\frac{k}{k_{i}}=\frac{k_{\infty}\left(1+\frac{b}{p}\right)}{k_{\infty}\left(1+\frac{b_{i}}{p_{i}}\right)}=\frac{1+\frac{b}{p}}{1+\frac{b_{i}}{p_{i}}}
$$

Considering that the unsaturated CBM reservoirs start to desorb coalbed methane only when the pressure declines to or below the critical desorption pressure, the mathematical form of the permeability variation model has been converted to:

$$
\frac{k}{k_{i}}=\frac{1+\frac{b}{p}}{1+\frac{b_{c}}{p_{c}}}
$$

